\title{
Synergistic protection of matrine and lycopene against lipopolysaccharide-induced acute lung injury in mice
}

\author{
WU-WEI LI ${ }^{1 *}$, TAO-YUAN WANG ${ }^{2 *}$, BO CAO $^{3,4}$, BIN LIU $^{2}$, YU-MEI RONG ${ }^{1}$, \\ JUAN-JUAN WANG ${ }^{2}$, FEI WEI $^{2}$, LU-QING WEI ${ }^{2},{\text { HONG } \text { CHEN }^{3} \text { and YAN-XIA LIU }}^{1}$
}

\begin{abstract}
${ }^{1}$ Department of Pharmacology, School of Basic Medical Sciences, Tianjin Medical University, Tianjin 300070; ${ }^{2}$ Department of Respiratory and Critical Care Medicine, Affiliated Hospital of Logistics University of Chinese People's Armed Police Force, Tianjin 300162; ${ }^{3}$ Department of Health Service, Logistics University of Chinese People's Armed Police Force, Tianjin 300300; ${ }^{4}$ Tianjin Key Laboratory of Cardiovascular Remodeling and Target Organ Injury, Tianjin 300162, P.R. China
\end{abstract}

Received August 20,2018; Accepted March 20, 2019

DOI: $10.3892 / \mathrm{mmr} .2019 .10278$

\begin{abstract}
Acute lung injury (ALI) is a major cause of morbidity and mortality globally, and is characterized by widespread inflammation in the lungs. Increased production of reactive oxygen species is hypothesized to be associated with ALI. Matrine and lycopene are active products present in traditional Chinese medicine. Matrine is an effective inhibitor of inflammation, whereas lycopene decreases lipid peroxidation. Therefore, it was hypothesized that combinatorial treatment with matrine and lycopene may provide synergistic protection against ALI. In the present study, mice were treated with dexamethasone (DEX; $5 \mathrm{mg} / \mathrm{kg}$ ), matrine ( $25 \mathrm{mg} / \mathrm{kg}$ ), lycopene (100 mg/kg), and matrine $(25 \mathrm{mg} / \mathrm{kg})+$ lycopene $(100 \mathrm{mg} / \mathrm{kg})$ for 7 days prior to injury induction using lipopolysaccharide (LPS; $5 \mathrm{mg} / \mathrm{kg}$ ) for $6 \mathrm{~h}$. Lung tissues were collected following the sacrifice of the mice and hematoxylin and eosin staining was used for histological analysis. Malondialdehyde (MDA), glutathione (GSH) and myeloperoxidas (MPO) levels were examined by respective kits. The expressions of interleukin-6 (IL-6) and tumor necrosis factor- $\alpha(\mathrm{TNF}-\alpha)$ were evaluated by ELISA. The expressions of $\mathrm{I} \kappa \mathrm{B} \alpha$ and NF- $\kappa \mathrm{B}$ p65 were examined by reverse transcription-quantitative polymerase chain reaction, western blotting and immunohistochemistry. The results indicated that
\end{abstract}

Correspondence to: Professor Yan-Xia Liu, Department of Pharmacology, School of Basic Medical Sciences, Tianjin Medical University, 22 Qixiangtai Road, Heping, Tianjin 300070, P.R. China E-mail: liu_yanxia126@126.com

Dr Bin Liu, Department of Respiratory and Critical Care Medicine, Affiliated Hospital of Logistics University of Chinese People's Armed Police Force, 220 Chenglin Road, Dongli, Tianjin 300162, P.R. China

E-mail: iamicehe@163.com

*Contributed equally

Key words: matrine, lycopene, acute lung injury, lipopolysaccharides, inflammation the combined treatment exhibited a similar effect to DEX, both of which attenuated lung structural injuries, downregulated the expressions of IL-6, TNF- $\alpha$, MPO and MDA, and upregulated that of GSH. Furthermore, the combined treatment and DEX inhibited $\mathrm{NF}-\kappa \mathrm{B}$ p 65 activation. The present study revealed that combined treatment with matrine and lycopene exhibited protective effects on an LPS-induced mouse model of ALI, suggesting that they may serve as a potential alternative to glucocorticoid therapy for ALI.

\section{Introduction}

Acute lung injury (ALI) is a serious respiratory condition with high morbidity (1) and mortality ( $35 \%)$ rates (2). It is characterized by damage to alveolar capillary membranes, atelectasis of lung airspaces, and infiltration of neutrophils and protein-rich fluid into the alveolar space (3-5). The mechanisms underlying ALI have not been fully determined. Potential mechanisms include inflammatory reactions $(6)$, apoptosis $(7,8)$ and redox imbalance (9). As a result, the majority of studies have focused on the imbalance of proinflammatory/antiinflammatory mediators and oxidation/reduction. Neutrophils have important roles in inflammatory processes; neutrophil transepithelial migration is an important pathological feature of ALI (10). Excessive or prolonged activation of neutrophils results in increased permeability of the alveolar/vascular barrier (10). Furthermore, neutrophils release proinflammatory and proapoptotic factors, damaging adjacent cells (10). In addition to neutrophils, free radicals also can damage lung structures (9). Massive production of free radicals leads to lipid peroxidation in lung tissues, promoting the apoptosis of alveolar epithelial cells and vascular endothelial cells (9). During the process, apoptosis induces oxidative stress $(7,8)$. This repeated cycle eventually leads to lung injury (9).

Matrine (MAT; Fig. 1A), a major active component extracted from the traditional Chinese herb Sophora flavescens Ait, is frequently used to treat diseases such as hepatitis, enteritis and atopic dermatitis in China (11). MAT exhibits various biological properties, of which immune modulation and anti-inflammation are the most prominent $(12,13)$. The carotene family is known to suppress oxidative damage 
by activating antioxidant enzymes and the stimulating the immune system (14). Lycopene (LY; Fig. 1B) is a member of the carotene family (15). As it has been reported that ALI involves superoxide radicals and inflammatory processes $(16,17)$, it was hypothesized that combined treatment with MAT and LY may protect the lungs from ALI. Therefore, in the present study, the effects of MAT, LY and MAT + LY on lipopolysaccharide (LPS)-induced ALI in mice were determined, and the mechanisms were preliminarily investigated. In addition, the efficacy of MAT, LY and MAT + LY were compared with dexamethasone (DEX), to explore the potential use of these compounds as alternatives to glucocorticoid therapy.

\section{Materials and methods}

Chemicals. MAT and LY ( $>98 \%$ purity) were obtained from the pharmaceutics laboratory of the Logistics University of Chinese People's Armed Police Force (PAPF; Tianjin, China). DEX was provided by the Affiliated Hospital of Logistics University of Chinese PAPF. LPS (055:B5) was purchased from Sigma-Aldrich (Merck KGaA). Antibodies used during the study included rabbit anti-IкB $\alpha$ (cat. no. CY5026; Abways Technology, Inc.), rabbit anti-phosphorylated (p)-IкB $\alpha$ (cat. no. 2859; Cell Signaling Technology, Inc.), rabbit anti-NF- $\kappa \mathrm{B}$ p65 (cat. no. 8242; Cell Signaling Technology, Inc.), rabbit anti-p-NF-кB p65 (cat. no. 3033; Cell Signaling Technology, Inc.), and horseradish peroxidase (HRP)-conjugated goat anti-rabbit IgG (cat. no. S0001; Affinity Biosciences). ELISA kits for the detection of interleukin-6 (IL-6; cat. no. E-EL-M0044c) and tumor necrosis factor- $\alpha$ (TNF- $\alpha$; cat. no. E-EL-M0049c) were purchased from Elabscience Biotechnology Co., Ltd. Kits for detecting the activity of malondialdehyde (MDA; cat. no. A003-1), glutathione (GSH; cat. no. A006-2) and myeloperoxidase (MPO; cat. no. A044) were purchased from Nanjing Jiancheng Bio-Engineering Institute Co., Ltd. TRIzol reagent and SuperRT One Step RT-PCR Kit (CW0742) for reverse transcription-polymerase chain reaction (RT-PCR) were purchased from Beijing CoWin Biotech Co., Ltd. Primers were purchased from Integrated DNA Technologies, Inc. BCA Protein Assay kit (cat. no. PC0020) and SDS-PAGE Gel Kit (cat. no. P1200) were purchased from Solarbio Co., Ltd. SPlink Detection kit (cat. no. SP-9001) for immunohistochemistry (IHC) was purchased from OriGene Technologies, Inc. All other chemicals were purchased from Beijing Dingguo Changsheng Biotechnology Co., Ltd.

Animals. Adult male BALB/c mice (18-22 g) were obtained from Vital River Laboratory Animal Technology Co., Ltd. The mice (aged 7 weeks old) were maintained in a 12-h light/dark cycle at $22 \pm 2^{\circ} \mathrm{C}$ with $60 \pm 10 \%$ humidity, and provided with sufficient food and water ad libitum. All animal experiments were approved by the Ethics Committee of Affiliated Hospital of Logistic University of Chinese People's Armed Police Force (permit no. AF-PJHEC-017-02.0), and were conducted in accordance with the guidelines set by the committee. A total of 36 mice were randomly divided into 6 groups: Control; $6 \mathrm{~h}$ LPS; DEX ( $5 \mathrm{mg} / \mathrm{kg})$ treatment $+6 \mathrm{~h} \mathrm{LPS}$; MAT $(25 \mathrm{mg} / \mathrm{kg})$ treatment + $6 \mathrm{~h} \mathrm{LPS}$; LY $(100 \mathrm{mg} / \mathrm{kg})$ treatment + LPS; and MAT $(25 \mathrm{mg} / \mathrm{kg})+\mathrm{LY}(100 \mathrm{mg} / \mathrm{kg})$ treatment $+6 \mathrm{~h}$ LPS. DEX

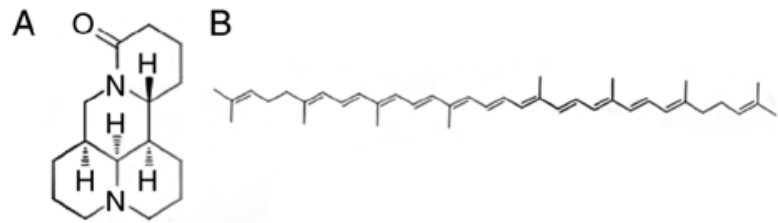

Figure 1. Chemical structures of matrine and lycopene. (A) Matrine is one of the main alkaloid constituents in Sophora flavescens Ait. (B) Lycopene is a carotenoid compound.

was administered via intraperitoneal injection for 7 consecutive days; MAT, LY, and MAT + LY combination treatments were administered orally for 7 consecutive days. The animals in the control group and LPS group received isovolumetric normal saline orally for the same period. At 30 min following the final administrations, the mice in all groups except the control group received an intratracheal instillation of LPS $(5 \mathrm{mg} / \mathrm{kg})$, whereas the animals in the control group received an intratracheal instillation of saline. At $6 \mathrm{~h}$ after LPS induction, the mice were euthanized via cervical dislocation following anesthetization with diethyl ether. Lung tissues were obtained and stored for further experiments.

Hematoxylin and eosin $(H \& E)$ staining. The lower lobe of right lungs were fixed with $4 \%$ paraformaldehyde at room temperature $\left(23 \pm 2^{\circ} \mathrm{C}\right)$ for 1 day, then dehydrated and embedded in paraffin. All samples in paraffin were cut into $5-\mu \mathrm{m}$ sections. For H\&E staining, sections were immersed in hematoxylin for $10 \mathrm{~min}$, followed by eosin for $3 \mathrm{~min}$ at room temperature. Following mounting using neutral balsam, the stained slides were observed under a light microscope (Olympus CHK; Olympus Corporation) and histopathology images were captured (C-4040 Zoom; Olympus Corporation). The lung injury score was assessed based on the method reported by Aeffner et al (18): No injury, 0; injury in $25 \%$ of the field, 1 ; injury in $50 \%$ of the field, 2 ; injury in $75 \%$ of the field, 3; and injury throughout the field, 4 . A total of 10 random microscopic images were acquired for each section, and the fields were scored blindly by two pathologists and averaged. After the lung injury scores were assessed, Q value was used to evaluate the synergistic protective effect (19). Q value was calculated as $\mathrm{E}_{\mathrm{A}+\mathrm{B}} /\left(\mathrm{E}_{\mathrm{A}}+\mathrm{E}_{\mathrm{B}}-\mathrm{E}_{\mathrm{A}} \bullet \mathrm{E}_{\mathrm{B}}\right)$. $\mathrm{E}_{\mathrm{A}}$ represents the average lung injury score in MAT group, $\mathrm{E}_{\mathrm{B}}$ represents the average lung injury score in LY group, and $\mathrm{E}_{\mathrm{A}+\mathrm{B}}$ represents the average lung injury score in MAT + LY group. Synergy or antagonism were defined by $\mathrm{Q}$ value $>1$ or $<1$ respectively, while $\mathrm{Q}=1$ indicated no interaction.

Lung wet-to-dry (W/D) weight ratios. The degree of pulmonary edema can be determined based on lung W/D weight ratios (20). Absorbent paper was used to absorb exudate and blood on the surface of superior lobes of right lungs. Then, the tissues were weighed and recorded as wet weights. The tissues were then dried at $70^{\circ} \mathrm{C}$ for $72 \mathrm{~h}$ to constant weight and recorded as dry weights. Lung W/D weight ratios=wet weight/dry weight.

$I H C$. The following steps, if not described otherwise, were all performed at room temperature $\left(23 \pm 2^{\circ} \mathrm{C}\right)$. Lung sections $(5 \mu \mathrm{m})$ were deparaffinized in xylene $(20 \mathrm{~min})$ and rehydrated 
A

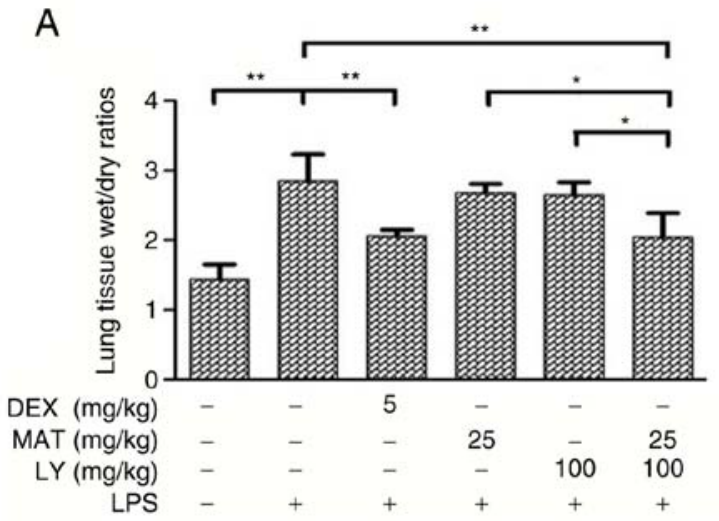

B

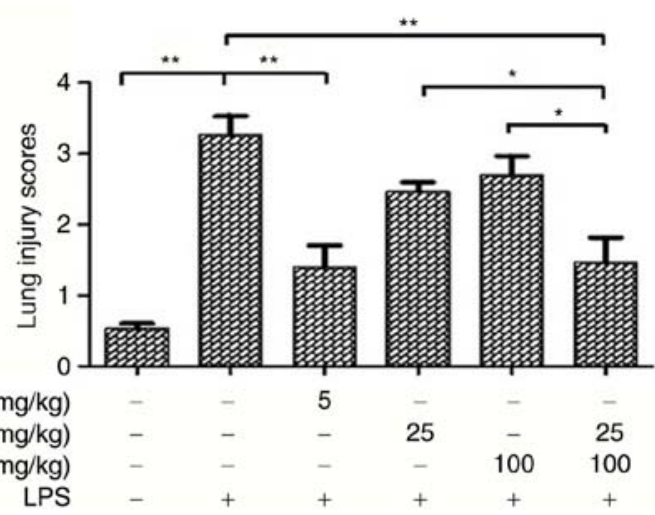

b

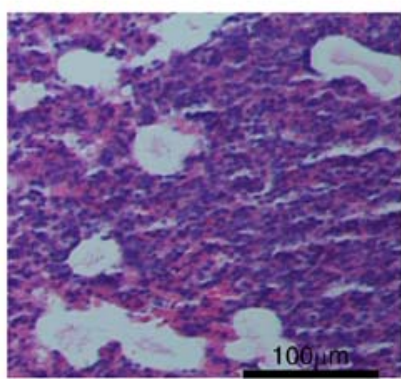

e

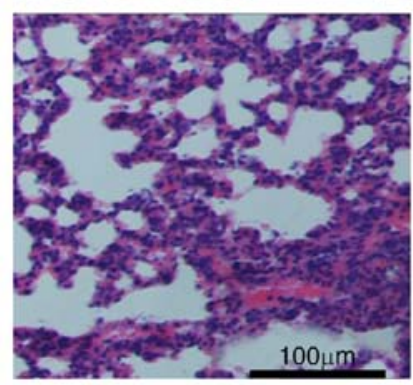

C

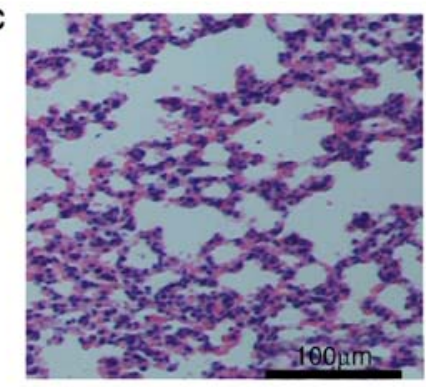

f

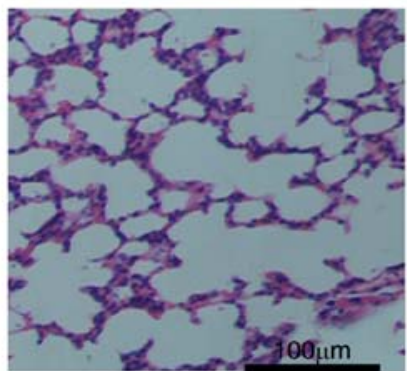

Figure 2. Edema and morphopathological alterations in lung tissues. (A) Superior lobes of right mouse lungs were extracted and weighed. Lung tissue wet/dry ratios=wet weight/dry weight. $n=6$. (B) Lung injury scores were determined by two pathologists. (C) Hematoxylin and eosin staining of the inferior lobes of right lungs: a, control; b, LPS; c, DEX + LPS; d, MAT + LPS; e, LY + LPS; and f, MAT + LY + LPS. Scale bar, $100 \mu$ m. Data are presented as the mean \pm standard deviation. ${ }^{*} \mathrm{P}<0.05,{ }^{* *} \mathrm{P}<0.01$. DEX, dexamethasone; MAT, matrine; LY, lycopene; LPS, lipopolysaccharide.

in a graded alcohol series (absolute ethyl alcohol for $10 \mathrm{~min}$, $90 \%$ alcohol for $5 \mathrm{~min}, 80 \%$ alcohol for $5 \mathrm{~min}, 70 \%$ alcohol for $5 \mathrm{~min}$ ). Antigens were retrieved in $0.01 \mathrm{M}$ citric acid heated by microwave for $20 \mathrm{~min}$. Endogenous peroxidases were inactivated by $3 \% \mathrm{H}_{2} \mathrm{O}_{2}$ for $20 \mathrm{~min}$. Goat serum was used to block for $1 \mathrm{~h}$ at $37^{\circ} \mathrm{C}$. Then, slides were incubated with diluted NF- $\kappa \mathrm{B}$ p65 antibody (1:500) overnight at $4^{\circ} \mathrm{C}$. The following day, the antibody was removed and the sections were washed with PBS prior to incubation with HRP-conjugated secondary antibody for $30 \mathrm{~min}$ at $37^{\circ} \mathrm{C}$. 3,3'-Diaminobenzidine was used to visualize expression and used to stain the slides for $5 \mathrm{~min}$. Finally, the slides were counterstained with hematoxylin for $30 \mathrm{sec}$ and dehydrated prior to observation under a light microscope. The results were evaluated semi-quantitatively. Five randomly fields were imaged from each section. Images were quantified using two different scores: Intensity score and positive cell ratio score. For the intensity score, negative, weakly positive, positive and strongly positive were graded as $0,1,2$ and 3 , respectively; for the positive cell ratio score, the positive cell area/the total area $<1 \%$ was scored $0 ; 1-10 \%$ scored $1 ;>10-50 \%$ scored 2 ; $>50-80 \%$ scored 3 ; and, $>80 \%$ scored 4 . The product of the two scores was used as the IHC value for each field.
ELISA for IL- 6 and TNF- $\alpha$. Mouse lung tissues were homogenized and then centrifuged at $12,000 \mathrm{x} g$ at $4^{\circ} \mathrm{C}$ for $20 \mathrm{~min}$. The supernatant was collected and diluted. The standard ELISA solutions or samples (diluent supernatant) were added to each well, then incubated for $90 \mathrm{~min}$ at $37^{\circ} \mathrm{C}$. Diluted biotin-labeled antibodies (1:99) were added to the wells, and the plates were covered and incubated for $2 \mathrm{~h}$ at $37^{\circ} \mathrm{C}$. The plates were then washed with washing buffer three times. HRP conjugate was then added to wells which allows binding with the biotin-labeled antibodies, and plates were incubated for $1 \mathrm{~h}$ at $37^{\circ} \mathrm{C}$. After washing the plates, the chemiluminescent substrate was detected using colorimetric 3,3',5,5'-tetramethylbenzidine solution. Finally, the stop solution was added into each well, and optical density of each well was read at $450 \mathrm{~nm}$ immediately by a microplate reader (Tecan Sunrise). The absorbance of samples was compared with the standard curve to calculate the concentration.

Western blot analysis. Total lung proteins were prepared from lung homogenates in RIPA buffer and protease/phosphatase inhibitor cocktail (Solarbio Co., Ltd.) and the protein concentration was determined by BCA method. Protein 
(30 $\mu \mathrm{g} / \mathrm{lane}$ ) was separated via SDS-PAGE on $10 \%$ gels and transferred to PVDF membranes. PVDF membranes were incubated with $5 \%$ non-fat milk at $25^{\circ} \mathrm{C}$ for $1 \mathrm{~h}$ with gentle agitation for blocking. Then, the membranes were incubated overnight with the aforementioned antibodies $(1: 1,000)$ at $4^{\circ} \mathrm{C}$. Following incubation with secondary antibodies $(1: 3,000)$ at $25^{\circ} \mathrm{C}$ for $1 \mathrm{~h}$, the blots were visualized using enhanced chemiluminescence reagent (cat. no. PE0010; Solarbio Co., Ltd.). ImageJ version 2.1.4.7 (National Institutes of Health) was used for densitometric quantification of expression.

Determination of MDA, GSH and MPO. Mouse lung tissues were homogenized, saline was added (tissue weight/g: Saline volume $/ \mathrm{ml}=1: 9$ ) and samples were centrifuged at $10,000 \mathrm{x} \mathrm{g}$ at $4^{\circ} \mathrm{C}$ for $10 \mathrm{~min}$. The supernatant was collected and used for subsequent experiments. MDA, GSH and MPO levels were detected using the respective kits, according to the manufacturer's protocols. The absorbances were measured at $532 \mathrm{~nm}$ for MDA, $405 \mathrm{~nm}$ for GSH, and $460 \mathrm{~nm}$ for MPO.

$R T$-PCR. Total RNA was isolated from lung tissues homogenates using TRIzol reagent (21), and RT-PCR was performed according to manufacturer's protocols. The kit allows reverse transcription and PCR in one step. The protocol includes 1 cycle at $45^{\circ} \mathrm{C}$ for $30 \mathrm{~min}$ followed by $95^{\circ} \mathrm{C}$ for $2 \mathrm{~min}$; then 40 cycles of $94^{\circ} \mathrm{C}$ for $30 \mathrm{sec}, 60^{\circ} \mathrm{C}$ for $30 \mathrm{sec}, 72^{\circ} \mathrm{C}$ for $30 \mathrm{sec}$; and, finally, 1 cycle at $72^{\circ} \mathrm{C}$ for $5 \mathrm{~min}$. The following primers were used: GAPDH, forward 5'-CCCAGCAAGGACACTGAGCAAG-3', reverse 5'-GGTCTGGGATGGAAATTGTGAGGG-3'; IL-6, forward 5'-GGATACCACTCCCAACAGACC-3', reverse 5'-TTCTGCAAGTGCATCATCGT-3'; TNF- $\alpha$, forward 5'-GGCCTCCCTCTCATCAGTTC-3', reverse 5'-CTTGGT GGTTTGCTACGACG-3'; and NF- $\kappa$ B p65, forward 5'-TCC GGTTACGTAATGAGTGGT-3' and reverse 5'-GATCTGGTT CTCTTTCCGAAGTC-3'. PCR products were resolved on $1.5 \%$ agarose gels via electrophoresis. Results were visualized using EtBr, and ImageJ version 2.1.4.7 (National Institutes of Health) was used to quantify expression.

Statistical analysis. SPSS version 17.0 (SPSS, Inc.) was used for data analysis. Data are expressed as the mean \pm standard deviation. Data were analyzed using one-way analysis of variance (ANOVA) followed by a Bonferroni test for multiple comparisons. For the lung injury scores and IHC values, the Kruskal-Wallis test was used, then all data were transformed logarithmically to make them conform to the normal distribution before using one-way ANOVA to compare specific groups. $\mathrm{P}<0.05$ was considered to indicate a statistically significant difference.

\section{Results}

$M A T+L Y$ treatment attenuates lung edema induced by LPS. As presented in Fig. 2A, LPS induction significantly increased the W/D ratio of lung tissues compared with the control group. The W/D ratios of tissues from the MAT-treated and LY-treated groups were similar, and were not significantly different to those from the LPS group; however, treatment with DEX or MAT + LY significantly decreased the W/D ratio compared with the LPS group.
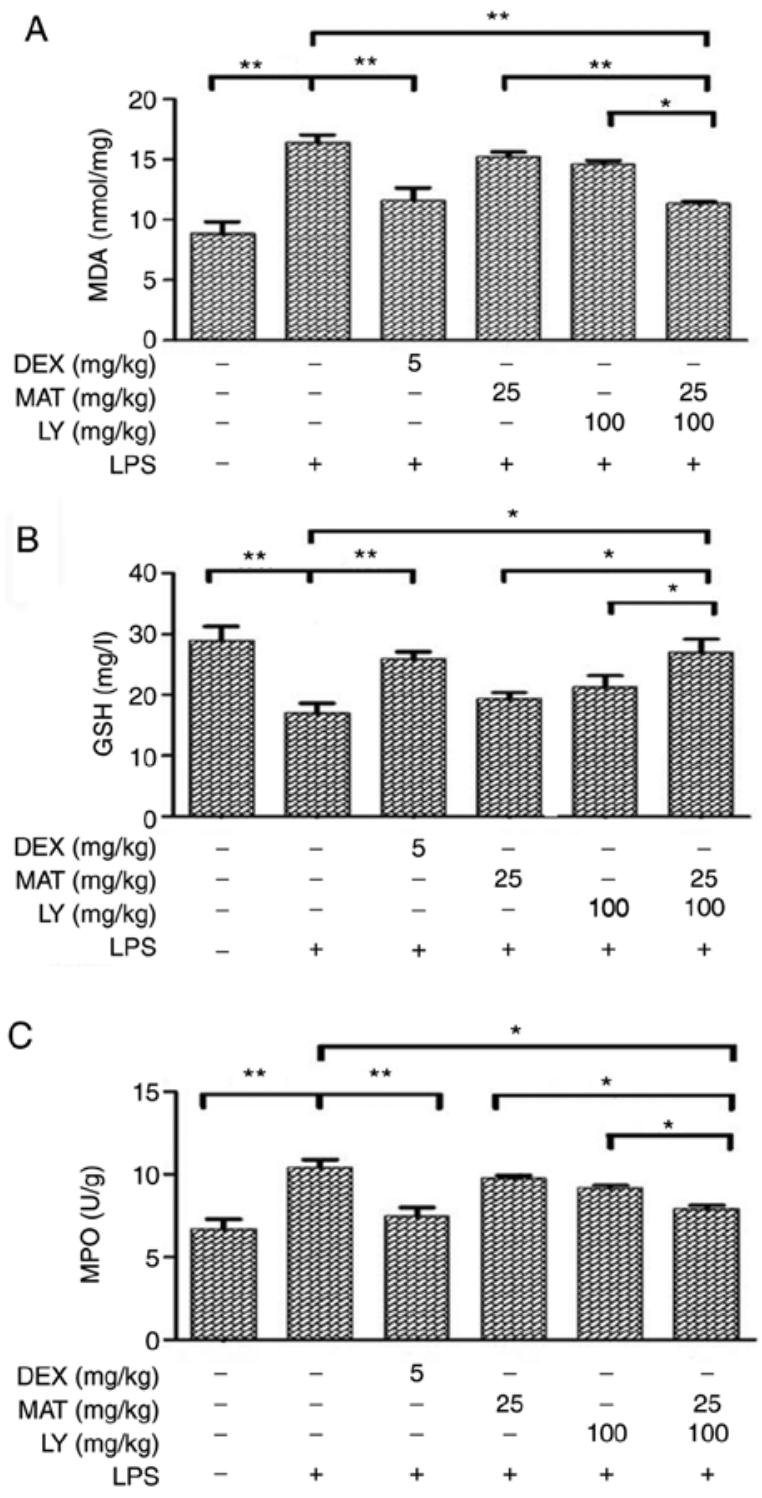

Figure 3. Levels of oxidative stress biomarkers in lung tissues. Lung tissues were collected and homogenized. Levels of (A) MDA, (B) GSH and (C) MPO were determined using respective kits. Data are presented as the mean \pm standard deviation. $\mathrm{n}=6 .{ }^{*} \mathrm{P}<0.05,{ }^{* *} \mathrm{P}<0.01$. MDA, malondialdehyde; DEX, dexamethasone; MAT, matrine; LY, lycopene; LPS, lipopolysaccharide; GSH, glutathione; MPO, myeloperoxidase.

$M A T+L Y$ treatment prevents histopathological changes to the lungs induced by LPS. The synergistic protective effects of MAT + LY were calculated using lung injury scores (Fig. 2B) and the $\mathrm{Q}$ value was 1.27 , indicating that MAT and $\mathrm{LY}$ exhibited synergy. As presented in Fig. 2C, lung tissues from the control group exhibited a normal lung structure, with the alveolar wall mainly composed of single layer of epithelial cells and possessing a complete structure. Conversely, hemorrhage, alveolar wall thickening, alveolar collapse and inflammatory infiltration were observed following LPS administration. The pathological alterations to the lungs were significantly attenuated by MAT + LY or DEX treatment (Fig. 2B and C), but were not significantly reduced in the MAT or LY only-treated groups.

$M A T+L Y$ treatment decreases oxidative stress in vivo. MDA is a product of lipid peroxidation and is frequently used 
A

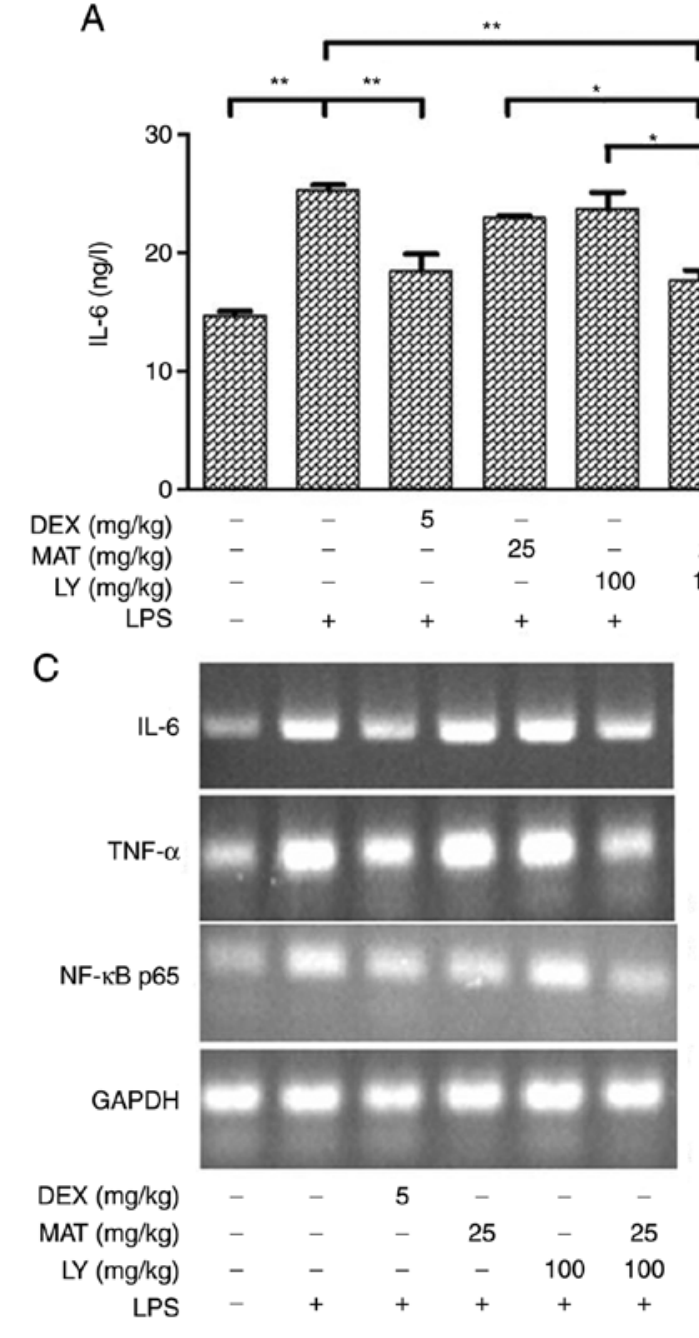

B
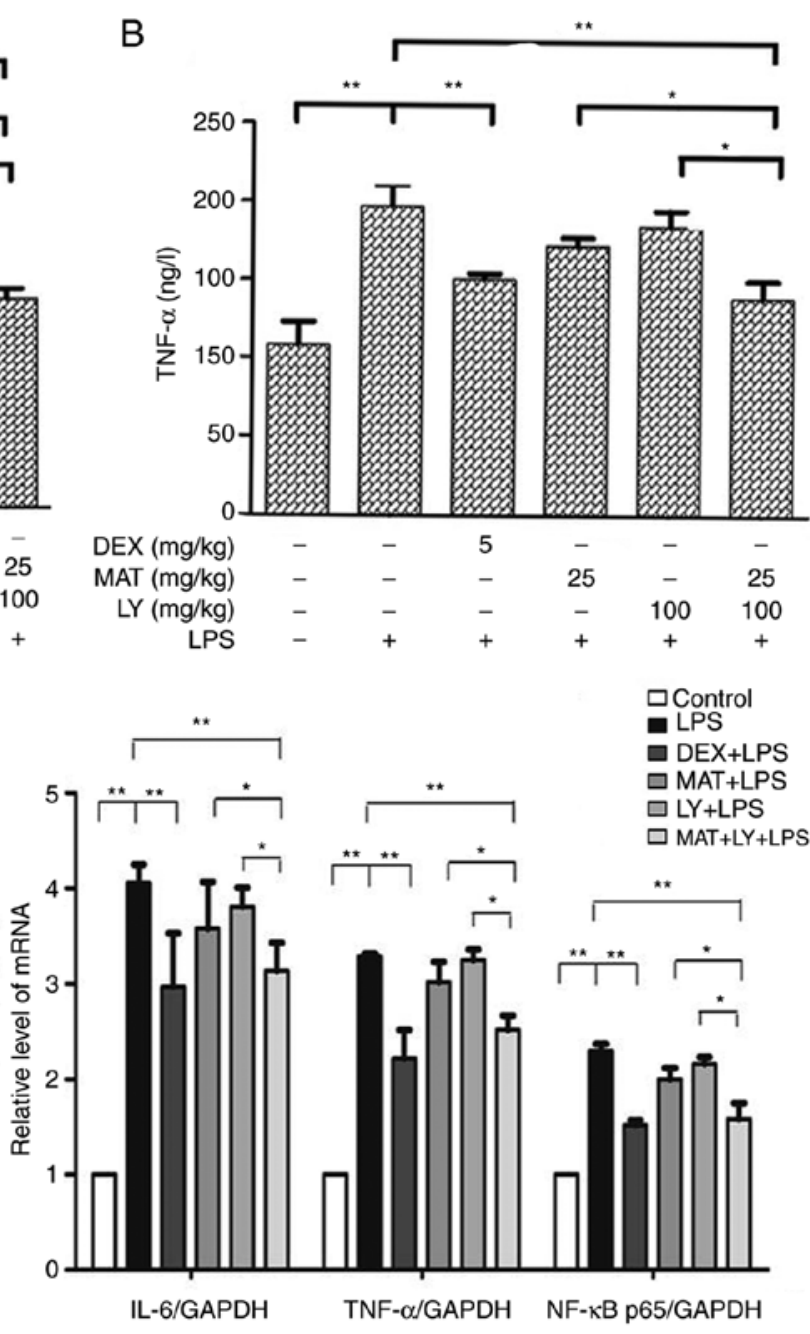

Figure 4. Levels of proinflammatory mediators in lung tissues. (A) IL-6 and (B) TNF- $\alpha$ levels in lungs as determined by ELISA. (C) Levels of IL-6, TNF- $\alpha$ and NF- $\kappa$ B p 65 mRNA as determined by semi-quantitative reverse transcription-polymerase chain reaction. The expression levels of mRNA were measured by densitometry and normalized to GAPDH mRNA expression levels. Data are presented as the mean \pm standard deviation. $\mathrm{n}=3$ for TNF- $\alpha$. $\mathrm{n}=5$ for IL- 6 and NF- $\mathrm{B}$ p65. ${ }^{*} \mathrm{P}<0.05,{ }^{* *} \mathrm{P}<0.01$. IL-6, interleukin-6; DEX, dexamethasone; MAT, matrine; LY, lycopene; LPS, lipopolysaccharide; TNF- $\alpha$, tumor necrosis factor- $\alpha$.

as biomarker for determining oxidative stress (22). MDA levels were significantly increased following LPS induction (Fig. 3A); however, treatments with MAT + LY or DEX significantly attenuated LPS-induced MDA increases. GSH is an important antioxidant used as a marker of oxidative stress (23). Administration of LPS induced a reduction in GSH (Fig. 3B). Treatment with MAT or LY alone increased GSH levels compared with the LPS group, although the differences were not statistically significant; however, combined treatment with MAT + LY or DEX significantly increased GSH levels. Furthermore, to determine the effects of MAT + LY on neutrophil accumulation, the levels of MPO were measured. Following intratracheal instillation of LPS, the levels of MPO in lung tissue were significantly elevated (Fig. 3C). MAT or LY treatment alone did not significantly affect MPO levels compared with the LPS group; however, the combination of treatment with MAT + LY significantly attenuated this LPS-induced increase.

$M A T+L Y$ treatment reduces the inflammatory response in vivo. The levels of IL-6 and TNF- $\alpha$ in lung tissues were determined via ELISA. The results indicated that the levels of IL-6 (Fig. 4A) and TNF- $\alpha$ (Fig. 4B) were significantly increased following LPS administration compared with the control group. Treatment with MAT or LY did not significantly affect the LPS-induced increased in IL- 6 or TNF- $\alpha$ levels, whereas treatment with MAT + LY or DEX significantly decreased the levels of IL- 6 and TNF- $\alpha$ compared with the LPS group. To further validate these results, IL-6 and TNF- $\alpha$ mRNA levels were measured via RT-PCR analysis, with the same trends observed (Fig. 4C).

$M A T+L Y$ treatment inhibits the $N F-\kappa B$ signaling pathway. $\mathrm{NF}-\kappa \mathrm{B}$ signaling pathway is a classical inflammatory signaling pathway. LPS activated the $\mathrm{I} \kappa \mathrm{B} / \mathrm{NF}-\kappa \mathrm{B}$ signaling, stimulating the expression of $\mathrm{NF}-\kappa \mathrm{B}$ p 65 compared with the control group (Figs. 4C and 5). Treatment with MAT or LY alone significantly inhibited $\mathrm{NF}-\kappa \mathrm{B}$ signaling, while the effect of MAT + LY was more pronounced. MAT +

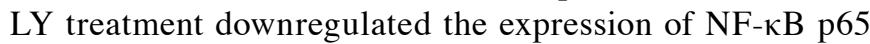
at the mRNA and protein levels, and the phosphorylation of NF- $\kappa \mathrm{B}$ p65 and $\mathrm{I} \kappa \mathrm{B} \alpha$ compared with the LPS group, 
A a
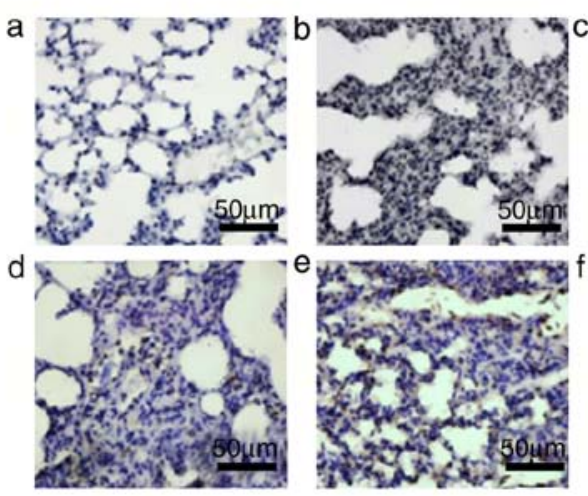

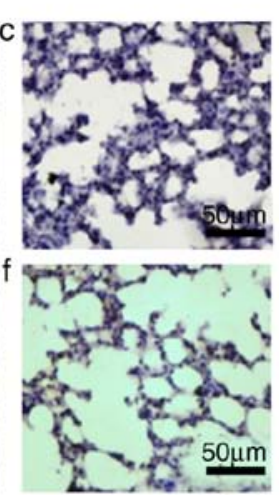

B

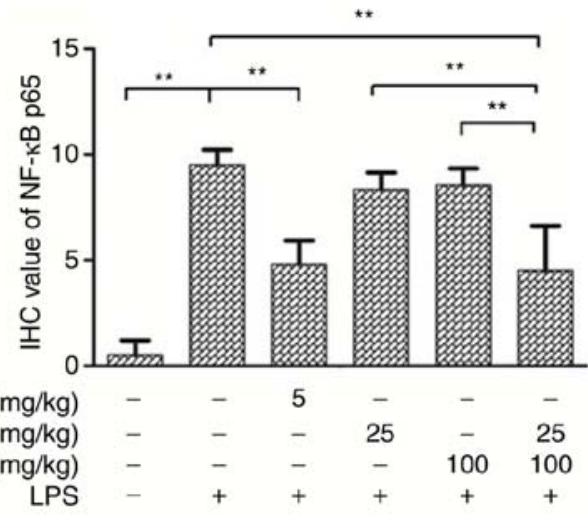

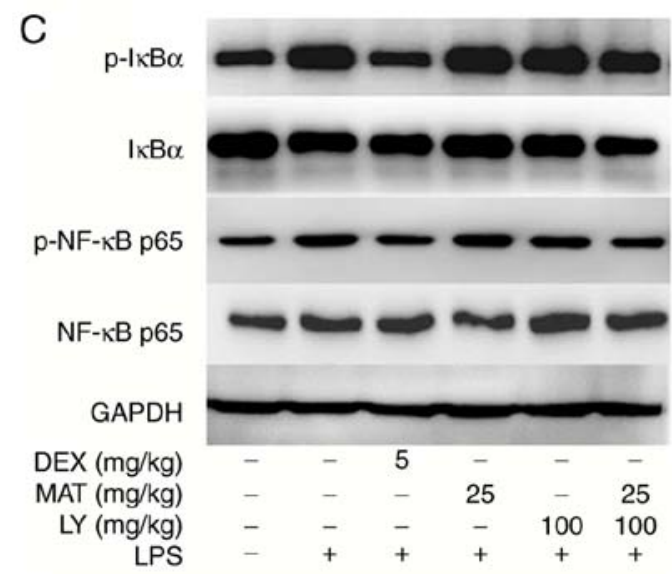

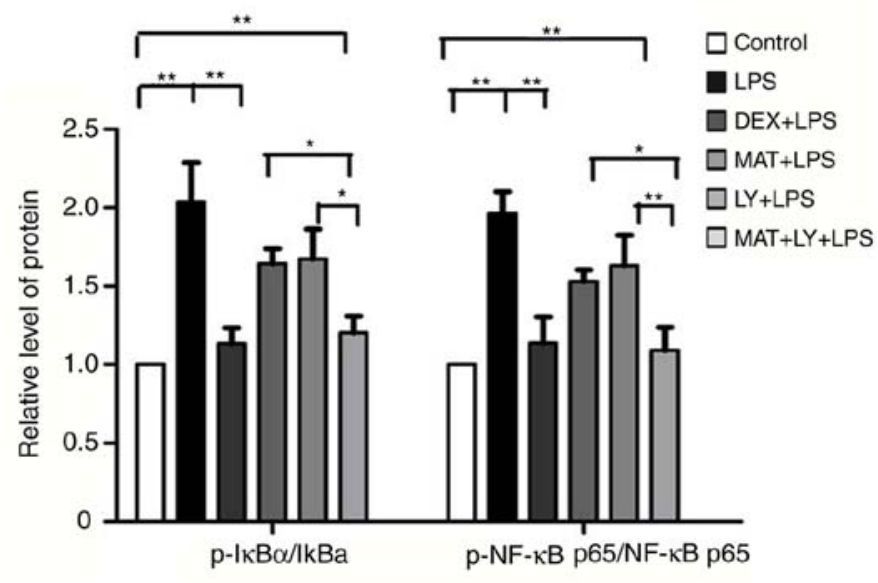

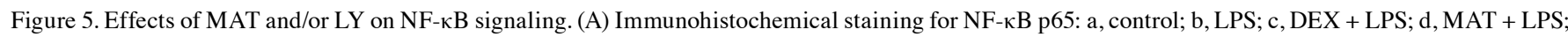
e, LY + LPS; and f, MAT + LY + LPS. Scale bar, $50 \mu \mathrm{m}$. (B) Protein expression of NF- $\mathrm{kB}$ p65 as evaluated semi-quantitatively based on immunohistochem-

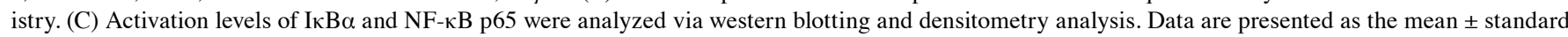
deviation. $\mathrm{n}=6 .{ }^{*} \mathrm{P}<0.05,{ }^{* *} \mathrm{P}<0.01$. DEX, dexamethasone; MAT, matrine; LY, lycopene; LPS, lipopolysaccharide.

inhibiting the activation of signaling induced by LPS (Fig. 5C).

\section{Discussion}

ALI is a serious disease characterized by bilateral lung infiltration. Various therapeutic interventions are under development; however, at present, there is no effective cure (24). The mortality rate of ALI is $30-40 \%$ (25). Glucocorticoids are potentially useful as anti-inflammatory drugs for the treatment of ALI (26); however, long-term use of glucocorticoids at high doses may lead to immunosuppression, resulting in infections that exacerbate the lung injury, or other complications, including Cushing's syndrome or psychiatric symptoms (27). It was previously reported that treatment with high doses of glucocorticoid for short or long periods of time did not improve the survival of patients with ALI (28). As a result, it is necessary to identify alternative treatments for ALI. Zhang et al (11) reported that intraperitoneal injection of MAT $(100 \mathrm{mg} / \mathrm{kg})$ protected against LPS-induced ALI in a mouse model. Türkoğlu et al (15) observed that LY (at 200 times the recommended daily intake in humans) exhibited protective effects in a rat model of oleic acid-induced ALI. The high doses and administration protocols in these studies restricted their clinical usefulness. Therefore, in the present study, these issues were amended; the two compounds were administered orally at a relatively low dosage, and their effects in combination were investigated.

LPS-induced lung injury in rodents is a frequently used ALI model, mimicking a number of the characteristics of ALI in humans (29). In the present study, combined treatment of MAT + LY achieved similar effects to DEX in protecting the lungs in the LPS-induced mouse model. The combination treatment attenuated lung injury and pulmonary edema, potentially via anti-inflammatory and antioxidative mechanisms, exhibiting synergistic effects.

The pathogenesis of ALI has not been fully determined. Inflammatory responses (30) and oxidative stress imbalances (31) have been identified to have important roles during the development and progression of ALI. These two mechanisms can affect the disease progression separately and synchronously. TNF- $\alpha$ is an early endogenous mediator of inflammatory responses produced by monocytes/macrophages (32). Excessive levels of TNF- $\alpha$ will damage lysosomes, leading to injuries in pulmonary vascular endothelial cells and epithelial cells (3). Furthermore, TNF- $\alpha$ induces the secretion of cytokines such as IL-6 (33). ELISA and RT-PCR analyses in the current study revealed that treatment with MAT alone markedly affected TNF- $\alpha$ and IL-6 levels; however, when LY was added, a significant decrease in the levels of the two cytokines was observed compared with the LPS group. 
Oxidative stress is increased during inflammation of airways, in turn exacerbating the inflammation (31). This leads to the formation of a positive feedback loop that promotes inflammatory responses, leading to deterioration of the condition (31). The release of reactive oxygen species (ROS), and subsequent induction of oxidative stress, has an important role in this process. ROS mainly attack polyunsaturated fatty acids in plasma membranes, inducing lipid peroxidation and increasing the levels of MDA $(34,35)$; thus, the levels of MDA reflect whether cells are subjected to attack by oxygen free radicals. In addition to interactions with inflammatory factors, ROS induce cell damage via a series of other mechanisms, such as the inactivation of antioxidant defense systems. The system includes various antioxidant enzymes, including superoxide dismutase and GSH peroxidase (31). These enzymes can reduce and eliminate the production of ROS, thereby protecting against damage caused by oxidative stress $(36,37)$. GSH is a member of the antioxidant defense system, and promotes the decomposition of hydrogen peroxide and inhibits the production of free radicals (38). GSH activity indicates the degree of endogenous oxygen free radical scavenging. LY is an antioxidant; however, $100 \mathrm{mg} / \mathrm{kg} \mathrm{LY}$ did not notably protect mice against ALI. It was observed that the recruitment of neutrophils was decreased when the mice were treated with MAT + LY, as determined by a significant decrease in MPO levels. MAT + LY also decreased the levels of lipid peroxidation in the mouse model of ALI, as determined by decreased MDA levels, and attenuated the reduction in GSH in lung tissue. The increase in GSH level in mice lung tissue may be a result of the upregulation of antioxidant expression or a decrease of ROS production.

The potential mechanism underlying the synergistic protective effect was investigated. $N F-\kappa B$ signaling has been identified as a traditional immune and inflammatory pathway. The $\mathrm{NF}-\kappa \mathrm{B} / \mathrm{Rel}$ family members are dimeric transcription factors. In the absence of stimulating signals, NF- $\kappa \mathrm{B}$ dimers are bound to inhibitory $\mathrm{I} \kappa \mathrm{B}$ proteins. In the canonical pathway, activators, such as proinflammatory cytokines, activate an I $\mathrm{B}$ kinase complex, leading to phosphorylation of $\mathrm{I} \kappa \mathrm{B}$ (39). Thus, the $\mathrm{NF}-\kappa \mathrm{B} / \mathrm{Rel}$ complexes are freed and further phosphorylated prior to translocation into the nucleus, where they induce gene expression (40). Treatment with MAT + LY significantly suppressed the LPS-induced activation of $\mathrm{NF}-\kappa \mathrm{B}$ activation compared with the single drug treatment groups. RT-PCR, western blot and IHC analyses indicated that the two agents inhibited $\mathrm{NF}-\kappa \mathrm{B}$ p 65 transcription and translation, in turn decreasing NF- $\kappa \mathrm{B}$ signaling. Specifically, MAT + LY treatment reduced the phosphorylation of $\mathrm{I} \kappa \mathrm{B} \alpha$, which allows $\mathrm{NF}-\kappa \mathrm{B}$ p65 to be anchored in the cytoplasm rather than phosphorylate and transfer to the nucleus to regulate proinflammatory gene transcription. The findings suggested that reduced signaling decreased the expression of proinflammatory factors, inhibiting the production of ROS and other oxygen radicals.

In conclusion, the results of the present study demonstrated that MAT or LY treatment alone exhibited limited protection against LPS-induced ALI in mice; however, combined treatment of MAT and LY significantly attenuated the LPS-induced alterations in cytokine expression and oxidative stress, suggesting that there may be a synergistic effect of the two chemicals. One of the mechanisms underlying this potential synergy was the inhibition of the $\mathrm{NF}-\kappa \mathrm{B}$ signaling pathway. The roles of other signaling pathways requires further investigation. Additionally, it should be noted that the pathology of ALI in clinical settings is more complex that in the mouse model. In the present study, drugs were administered for 7 days prior to LPS induction, an unlikely situation in a clinical setting. Additional groups and time points will be explored in future experiments. According to the present findings, the combined administration of MAT and LY may be a potential alternative to glucocorticoid therapy for the treatment of ALI.

\section{Acknowledgements}

Not applicable.

\section{Funding}

The present study was supported by the Key Laboratory for Occupational and Environmental Hazards Prevention of Tianjin (grant no. WHKF201705) and the National Natural Science Foundation of China (grant no. 81600051).

\section{Availability of data and materials}

The datasets used and/or analyzed during the present study are available from the corresponding author on reasonable request.

\section{Authors' contributions}

WL and TW were major contributors in writing the manuscript. WL, YR and JW performed the experiments and analyzed the data. TW, BC and BL contributed to the conception and design of the study. FW and LW performed the histological examination. HC and YL designed the present study and revised the manuscript. All authors read and approved the final manuscript.

\section{Ethics approval and consent to participate}

Animal experiments were approved by the Ethics Committee of Affiliated Hospital of Logistic University of Chinese People's Armed Police Force (permit number: AF-PJHEC-017-02.0), and were conducted in accordance with the guidelines set by the committee.

\section{Patient consent for publication}

Not applicable.

\section{Competing interests}

The authors declare that they have no competing interests.

\section{References}

1. Bersten AD, Edibam C, Hunt T and Moran J; Australian and New Zealand Intensive Care Society Clinical Trials Group: Incidence and mortality of acute lung injury and the acute respiratory distress syndrome in three Australian States. Am J Respir Crit Care Med 165: 443-448, 2002.

2. Erickson SE, Martin GS, Davis JL, Matthay MA and Eisner MD; NIH NHLBI ARDS Network: Recent trends in acute lung injury mortality: 1996-2005. Crit Care Med 37: 1574-1579, 2009. 
3. Zhong WT, Wu YC, Xie XX, Zhou X, Wei MM, Soromou LW, $\mathrm{Ci} X \mathrm{X}$ and Wang DC: Phillyrin attenuates LPS-induced pulmonary inflammation via suppression of MAPK and NF- $\kappa \mathrm{B}$ activation in acute lung injury mice. Fitoterapia 90: 132-139, 2013

4. Zhang X, Li C, Li J, Xu Y, Guan S and Zhao M: Protective effects of protocatechuic acid on acute lung injury induced by lipopolysaccharide in mice via $\mathrm{p} 38 \mathrm{MAPK}$ and NF- $\mathrm{B}$ signal pathways. Int Immunopharmacol 26: 229-236, 2015.

5. Zhang Y, Liang D, Dong L, Ge X, Xu F, Chen W, Dai Y, Li H, Zou P, Yang S and Liang G: Anti-inflammatory effects of novel curcumin analogs in experimental acute lung injury. Respir Res 16: 43, 2015.

6. Menezes SL, Bozza PT, Neto HC, Laranjeira AP, Negri EM, Capelozzi VL, Zin WA and Rocco PR: Pulmonary and extrapulmonary acute lung injury: Inflammatory and ultrastructural analyses. J Appl Physiol (1985) 98: 1777-1783, 2005.

7. Chopra M, Reuben JS and Sharma AC: Acute lung injury: Apoptosis and signaling mechanisms. Exp Biol Med (Maywood) 234: 361-371, 2009.

8. Z'graggen BR, Tornic J, Müller-Edenborn B, Reyes L, Booy C and Beck-Schimmer B: Acute lung injury: Apoptosis in effector and target cells of the upper and lower airway compartment. Clin Exp Immunol 161: 324-331, 2010.

9. Sarma JV and Ward PA: Oxidants and redox signaling in acute lung injury. Compr Physiol 1: 1365-1381, 2011.

10. Zemans RL, Colgan SP and Downey GP: Transepithelial migration of neutrophils: Mechanisms and implications for acute lung injury. Am J Respir Cell Mol Biol 40: 519-535, 2009.

11. Zhang B, Liu ZY, Li YY, Luo Y, Liu ML, Dong HY, Wang YX Liu Y, Zhao PT, Jin FG and Li ZC: Antiinflammatory effects of matrine in LPS-induced acute lung injury in mice. Eur $\mathrm{J}$ Pharm Sci 44: 573-579, 2011

12. Niu Y, Dong Q and Li R: Matrine regulates Th1/Th2 cytokine responses in rheumatoid arthritis by attenuating the NF- $\mathrm{BB}$ signaling. Cell Biol Int 41: 611-621, 2017.

13. Huang WC, Chan CC, Wu SJ, Chen LC, Shen JJ, Kuo ML, Chen MC and Liou CJ: Matrine attenuates allergic airway inflammation and eosinophil infiltration by suppressing eotaxin and Th2 cytokine production in asthmatic mice. J Ethnopharmacol 151 470-477, 2014

14. Prabhala RH, Braune LM, Garewal HS and Watson RR: Influence of beta-carotene on immune functions. Ann N Y Acad Sci 691 262-263, 1993.

15. Türkoğlu S, Muz MH, Ozercan R, Gürsu F and Kırkıl G: Effects of lycopene on the model of oleic acid-induced acute lung injury. Tuberk Toraks 60: 101-107, 2012.

16. Allen TC and Kurdowska A: Interleukin 8 and acute lung injury. Arch Pathol Lab Med 138: 266-269, 2014.

17. Mokra D and Kosutova P: Biomarkers in acute lung injury. Respir Physiol Neurobiol 209: 52-58, 2015.

18. Aeffner F, Bolon B and Davis IC: Mouse models of acute respiratory distress syndrome: A review of analytical approaches, pathologic features, and common measurements. Toxicol Pathol 43: 1074-1092, 2015

19. Zhang D, Liu B, Cao B, Wei F, Yu X, Li GF, Chen H, Wei LQ and Wang PL: Synergistic protection of Schizandrin B and Glycyrrhizic acid against bleomycin-induced pulmonary fibrosis by inhibiting TGF- $\beta 1 / \mathrm{Smad} 2$ pathways and overexpression of NOX4. Int Immunopharmacol 48: 67-75, 2017.

20. Parker JC and Townsley MI: Evaluation of lung injury in rats and mice. Am J Physiol Lung Cell Mol Physiol 286: L231-L246, 2004

21. Chomczynski P and Sacchi N: Single-step method of RNA isolation by acid guanidinium thiocyanate-phenol-chloroform extraction. Anal Biochem 162: 156-159, 1987.
22. GawełS, Wardas M,Niedworok Eand WardasP: Malondialdehyde (MDA) as a lipid peroxidation marker. Wiad Lek 57: 453-455, 2004 (In Polish).

23. Mytilineou C, Kramer BC and Yabut JA: Glutathione depletion and oxidative stress. Parkinsonism Relat Disord 8: 385-387, 2002.

24. Del Sorbo L, Goffi A and Ranieri VM: Mechanical ventilation during acute lung injury: Current recommendations and new concepts. Presse Med 40: e569-e583, 2011.

25. Su ZQ, Mo ZZ, Liao JB, Feng XX, Liang YZ, Zhang X, Liu YH, Chen XY, Chen ZW, Su ZR and Lai XP: Usnic acid protects LPS-induced acute lung injury in mice through attenuating inflammatory responses and oxidative stress. Int Immunopharmacol 22: 371-378, 2014

26. Thompson BT: Glucocorticoids and acute lung injury. Crit Care Med 31 (Suppl 4): S253-S257, 2003.

27. Oray M, Abu Samra K, Ebrahimiadib N, Meese H and Foster CS: Long-term side effects of glucocorticoids. Expert Opin Drug Saf 15: 457-465, 2016.

28. Steinberg KP, Hudson LD, Goodman RB, Hough CL, Lanken PN, Hyzy R, Thompson BT and Ancukiewicz M; National Heart, Lung, and Blood Institute Acute Respiratory Distress Syndrome (ARDS) Clinical Trials Network: Efficacy and safety of corticosteroids for persistent acute respiratory distress syndrome. N Engl J Med 354: 1671-1684, 2006.

29. Rittirsch D, Flierl MA, Day DE, Nadeau BA, McGuire SR, Hoesel LM, Ipaktchi K, Zetoune FS, Sarma JV, Leng L, et al: Acute lung injury induced by lipopolysaccharide is independent of complement activation. J Immunol 180: 7664-7672, 2008.

30. Ward PA: Acute lung injury: How the lung inflammatory response works. Eur Respir J (Suppl 44): S22-S23, 2003.

31. Ward PA: Oxidative stress: Acute and progressive lung injury. Ann N Y Acad Sci 1203: 53-59, 2010.

32. Zelová $H$ and Hošek J: TNF- $\alpha$ signalling and inflammation: Interactions between old acquaintances. Inflamm Res 62: 641-651, 2013.

33. Ohta K, Naruse T, Ishida Y, Shigeishi H, Nakagawa T, Fukui A Nishi H, Sasaki K, Ogawa I and Takechi M: TNF- $\alpha$-induced IL-6 and MMP-9 expression in immortalized ameloblastoma cell line established by hTERT. Oral Dis 23: 199-209, 2017.

34. Faurschou M and Borregaard N: Neutrophil granules and secretory vesicles in inflammation. Microbes Infect 5: 1317-1327, 2003.

35. Macdonald J, Galley HF and Webster NR: Oxidative stress and gene expression in sepsis. Br J Anaesth 90: 221-232, 2003.

36. Victor VM, Rocha M and De la Fuente M: Immune cells: Free radicals and antioxidants in sepsis. Int Immunopharmacol 4: 327-347, 2004.

37. Del Rio D, Stewart AJ and Pellegrini N: A review of recent studies on malondialdehyde as toxic molecule and biological marker of oxidative stress. Nutr Metab Cardiovasc Dis 15: 316-328, 2005.

38. Schettler V,Wieland E, Methe H,Schuff-Werner P and Müller GA Oxidative stress during dialysis: Effect on free radical scavenging enzyme (FRSE) activities and glutathione (GSH) concentration in granulocytes. Nephrol Dial Transplant 13: 2588-2593, 1998.

39. Hinz $\mathrm{M}$ and Scheidereit $\mathrm{C}$ : The $\mathrm{I} \kappa \mathrm{B}$ kinase complex in NF- $\kappa \mathrm{B}$ regulation and beyond. EMBO Rep 15: 46-61, 2014.

40. Luo K: Signaling CROSS Talk between TGF- $\beta /$ Smad and other signaling pathways. Cold Spring Harb Perspect Biol 9: a022137, 2017.

This work is licensed under a Creative Commons Attribution-NonCommercial-NoDerivatives 4.0 International (CC BY-NC-ND 4.0) License. 